\title{
Fast Switching Electrochromic Devices Containing Optimized BEMA/PEGMA Gel Polymer Electrolytes
}

\author{
N. Garino, ${ }^{1,2}$ S. Zanarini, ${ }^{1}$ S. Bodoardo, ${ }^{1}$ J. R. Nair, ${ }^{1}$ S. Pereira, ${ }^{3}$ L. Pereira, ${ }^{3}$ R. Martins, ${ }^{3}$ \\ E. Fortunato, ${ }^{3}$ and N. Penazzi ${ }^{1}$ \\ ${ }^{1}$ Department of Applied Science and Technology-DISAT, Politecnico di Torino, C.so Duca degli Abruzzi 24, 10129 Turin, Italy \\ ${ }^{2}$ Center for Space Human Robotics at Polito, Italian Institute of Technology-IIT, Corso Trento 21, 10129 Turin, Italy \\ ${ }^{3}$ CENIMAT/I3N, Departamento de Ciência dos Materiais, Faculdade de Ciências e Tecnologia, FCT, \\ Universidade Nova de Lisboa (UNL), 2829-516 Caparica, Portugal
}

Correspondence should be addressed to S. Zanarini; simone.zanarini@unibo.it

Received 27 May 2013; Revised 29 August 2013; Accepted 30 August 2013

Academic Editor: Sheng S. Zhang

Copyright $\odot 2013$ N. Garino et al. This is an open access article distributed under the Creative Commons Attribution License, which permits unrestricted use, distribution, and reproduction in any medium, provided the original work is properly cited.

\begin{abstract}
An optimized thermoset gel polymer electrolyte based on Bisphenol A ethoxylate dimethacrylate and Poly(ethylene glycol) methyl ether methacrylate (BEMA/PEGMA) was prepared by facile photo-induced free radical polymerisation technique and tested for the first time in electrochromic devices (ECD) combining $\mathrm{WO}_{3}$ sputtered on ITO as cathodes and $\mathrm{V}_{2} \mathrm{O}_{5}$ electrodeposited on ITO as anodes. The behaviour of the prepared ECD was investigated electrochemically and electro-optically. The ECD transmission spectrum was monitored in the visible and near-infrared region by varying applied potential. A switching time of ca. $2 \mathrm{~s}$ for $\mathrm{Li}^{+}$insertion (coloring) and of ca. $1 \mathrm{~s}$ for $\mathrm{Li}^{+}$de-insertion (bleaching) were found. UV-VIS spectroelectrochemical measurements evidenced a considerable contrast between bleached and colored state along with a good stability over repeated cycles. The reported electrochromic devices showed a considerable enhancement of switching time with respect to the previously reported polymeric ECD indicating that they are good candidates for the implementation of intelligent windows and smart displays.
\end{abstract}

\section{Introduction}

Recently electrochromic (EC) materials have attracted considerable attention due to their potential application in several types of optical devices including intelligent windows and smart displays. They can change colour in a persistent and reversible way by potential-promoted ion insertion/deinsertion mechanism. Generally, this colour response is induced by the application of a low-dc potential [1]. The mounting interest in the use of these materials on electrochromic devices (ECD) is mainly due to the high visibility and high reflective contrast ratio compared to other displays, for example, LCD without backlighting. EC materials are generally inorganic oxides that can be divided between those changing colour under ions insertion (cathode) and those changing colour during ions de-insertion (anode). Many transition metal (W, Ir, Mn, Co) oxides have been studied for their electrochromic behaviour and stability with respect to the organic ones [1]. One of the first candidates studied for such application was tungsten oxide $\left(\mathrm{WO}_{3}\right)$ [2-4]. In particular, the surfactant assisted electrochemical synthesis of $\mathrm{WO}_{3}$ [5] is one of the most promising methods for the production of nanostructured powders suitable for inks formulations. The counter electrode, in general, is considered the limiting factor in the EC device [6]. Vanadium oxide $\left(\mathrm{V}_{2} \mathrm{O}_{5}\right)$ is a good candidate for EC devices as it is a lithium battery cathode material, which shows different colours with $\mathrm{Li}^{+}$-ion insertion and it can therefore be proposed as an adequate counter electrode in rocking-chair ECDs. $\mathrm{V}_{2} \mathrm{O}_{5}$ based thin films can be prepared by various techniques [7], such as sol-gel, electrochemical, and vacuum deposition, for for example, evaporation [8] and sputtering [9]. The effect of mesoporosity on the kinetics of $\mathrm{V}_{2} \mathrm{O}_{5}$ thin films, investigated by Liu et al. [10], showed that an enhanced charge-discharge rate for porous samples can be achieved. The in situ optical measurements showed a multicolour EC 
effect of the film resulting in lower switching time and higher control over transmittance. The monitoring of morphology and crystallinity during deposition is then fundamental to achieve high electro-optical performances. On the other hand, one of the most important factors affecting the switching time is the electrolyte optimization. Liquid electrolytes exhibit low stability, high flammability, and low safety by limiting the possible wide range application of ECDs. To enhance the range of application and also to address the above mentioned problems, solid polymer electrolytes have been suggested as an important ion conducting medium [11]. Actually, polymer electrolytes can guarantee good contact with the electrodes, simple preparation procedures can be adopted, low production cost and good mechanical properties [12] can be obtained along with improved safety, stability and reliability. The polymeric electrolytes are so versatile that the final properties can be finely tuned according to the targeted requirements. Thermoset membranes prepared by UV-induced free-radical photo-polymerization technique could be an interesting alternative to the existing systems as this process has excellent versatility in application. It is a well-established polymerization technique, taking place at ambient temperature under UV light. The potentials of this technique, commonly employed for the preparation of coatings, inks, and for the production of optical and electronic devices, can be diverted to our field of interest to obtain very fast, low cost production and to have an environmentally friendly approach, as the use of solvents is almost avoided. In fact, highly cross-linked polymers are readily synthesized by irradiating an appropriate formulation of multifunctional monomers, namely, acrylates and methacrylates, in the presence of a photo initiator [12-14].

In the present work an optimized BEMA/PEGMA(Bisphenol A ethoxylate dimethacrylate and Poly(ethylene glycol) methyl ether methacrylate) based thermoset polymer electrolyte formulation [15] was prepared by in situ UV curing technique between appropriate EC electrodes [16] and tested for the first time in electrochromic devices (ECD). The polymer electrolytes exhibited high ionic conductivity $\left(10^{-3} \mathrm{~S} \cdot \mathrm{cm}^{-1}\right.$ at room temperature) [11, 17-19]. Quasi solid state electrochromic devices were successfully realized by using $\mathrm{WO}_{3}$ and $\mathrm{V}_{2} \mathrm{O}_{5}$ films deposited on Indium-doped tin oxide- (ITO) based substrates as electrodes and the optimized BEMA/PEGMA based gel polymer as electrolyte and separator. The aim was to obtain an high contrast device with short switching time and enhanced time stability.

\section{Methods and Materials}

2.1. Electrodes Preparation. The electrodes of EC devices were prepared by two different techniques, namely, electrochemical deposition and sputtering. ITO coated PET (SigmaAldrich, $R=60 \Omega / \mathrm{sq}, T>75 \%$ at $550 \mathrm{~nm}$ ) was used as conductive substrate for anodes and ITO coated glass (SigmaAldrich, $R=25 \Omega / \mathrm{sq}$ ) was used as conductive substrate for cathodes. All the slides were carefully rinsed with ethanol and acetone and dried prior to use. $\mathrm{V}_{2} \mathrm{O}_{5}$ (most likely in the
$\mathrm{H}_{3} \mathrm{VO}_{4}$ or $\mathrm{V}_{2} \mathrm{O}_{5} \cdot x \mathrm{H}_{2} \mathrm{O}$ form as suggested by the presence of $-\mathrm{OH}$ vibrations in the FTIR spectrum reported below) was deposited on ITO/PET anodes by an electrochemical method: $0.16 \mathrm{~g}$ of $\mathrm{VOSO}_{4} \cdot 3 \mathrm{H}_{2} \mathrm{O}$ were dissolved in a $1: 1 \mathrm{v} / \mathrm{v}$ water/ethanol solution $(8 \mathrm{~mL})$. The suspension stability was assured by the addition $0.16 \mathrm{~g}$ of nonionic surfactant (P123, Sigma-Aldrich) [10]. ITO/PET foils were cut into pieces of appropriate size and transferred to the deposition solution bath; ITO/PET sheets were used as working electrode and a Pt foil was used as counter and reference electrode. EC films over the ITO/PET were obtained by applying a positive potential for few seconds at galvanostatic conditions (current density $=1 \mathrm{~mA} / \mathrm{cm}^{2}, T=20^{\circ} \mathrm{C}$ ) [10]. After the deposition, the anodes were soaked in ethanol for 10 minutes to remove the residual surfactant and subsequently dried in air for $6 \mathrm{~h}$. Transparent and uniform yellow coatings were clearly visible at the conducting surface of the working electrode by naked eyes. Different coloration intensities were obtained by varying the deposition time (5-60 s). The typical thickness of $\mathrm{V}_{2} \mathrm{O}_{5}$ films on ITO used as anodes in this work, estimated by SEM cross sections (not shown), was of ca. $2 \mu \mathrm{m}$. The deposition area was designed by an adhesive PET film, that served also mould and spacer during the polymer electrolyte deposition (see Section 2.3) to obtain a cathode-anode separation of ca. $100 \mu \mathrm{m} . \mathrm{WO}_{3}$ thin films (cathodes) were prepared on ITO/glass at room temperature by RF magnetron sputtering (Pfeiffer Balzer 500 Sputtering). A tungsten oxide target (purity $=99,95 \%$ ) under the reactive atmosphere (oxygen partial pressure $=1 \times 10^{-3}$ mbar, Argon partial pressure $1.9 \times$ $10^{-2} \mathrm{mbar}$, deposition pressure $2 \times 10^{-2} \mathrm{mbar}$ ) was employed for the deposition with a target to substrate distance of $15 \mathrm{~cm}$ and a power of $200 \mathrm{~W}$ (deposition time: 60 minutes), to obtain a film thickness of ca. $300 \mathrm{~nm}$.

Typical Cyclic voltammograms of $\mathrm{WO}_{3}$ and $\mathrm{V}_{2} \mathrm{O}_{5}$ prepared films on ITO substrate are shown in Figure 1. The shape and position of oxidation and reduction peaks are in good agreement with the literature confirming the successful deposition and electrochemical activity of cathodic and anodic materials [1].

2.2. Polymer Electrolyte Preparation. The reactive formulation for the preparation of the polymer electrolyte membrane was based on Bisphenol A ethoxylate $(15 \mathrm{EO} / \mathrm{phenol})$ dimethacrylate (BEMA) [20], a methacrylic-based di-functional oligomer with an average molecular weight of 1700 , obtained from Aldrich. Poly(ethylene glycol) methyl ether methacrylate (PEGMA, Mn $=475$, Aldrich) was used as the reactive diluent $[11,20]$. Bis(trifluoromethane)sulfonamide lithium salt (LiTFSI, $\mathrm{CF}_{3} \mathrm{SO}_{2} \mathrm{NLiSO}_{2} \mathrm{CF}_{3}$, battery grade), obtained from Ferro Corp. (USA), was used as the $\mathrm{Li}^{+}$ions source. A 1:1 w/w ethylene carbonate-diethyl carbonate (ECDEC, battery grade, Ferro Corp., USA) solution was used as an organic plasticizer. 2-hydroxy-2-methyl-1-phenyl-1propanone (Darocur 1173/D1173) provided by Ciba Specialty Chemicals was used as the free radical photo-initiator. Before their use, BEMA, PEGMA, and D1173 were kept open for several days in the inert atmosphere of a dry glove box (MBraun Labstar, $\mathrm{O}_{2}$ and $\mathrm{H}_{2} \mathrm{O}$ content $<0.1 \mathrm{ppm}$ ) filled with extra pure 


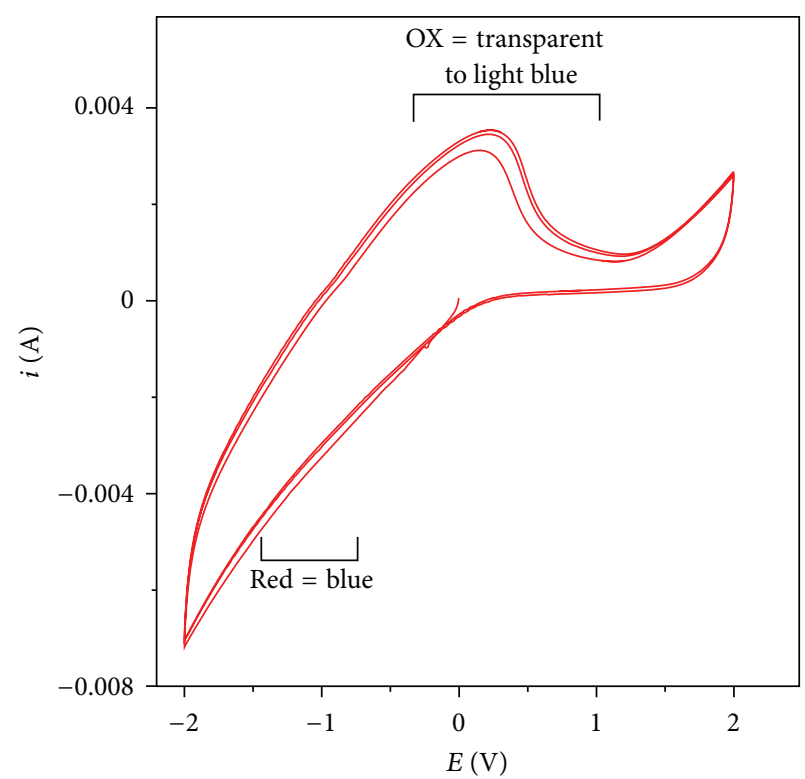

(a)

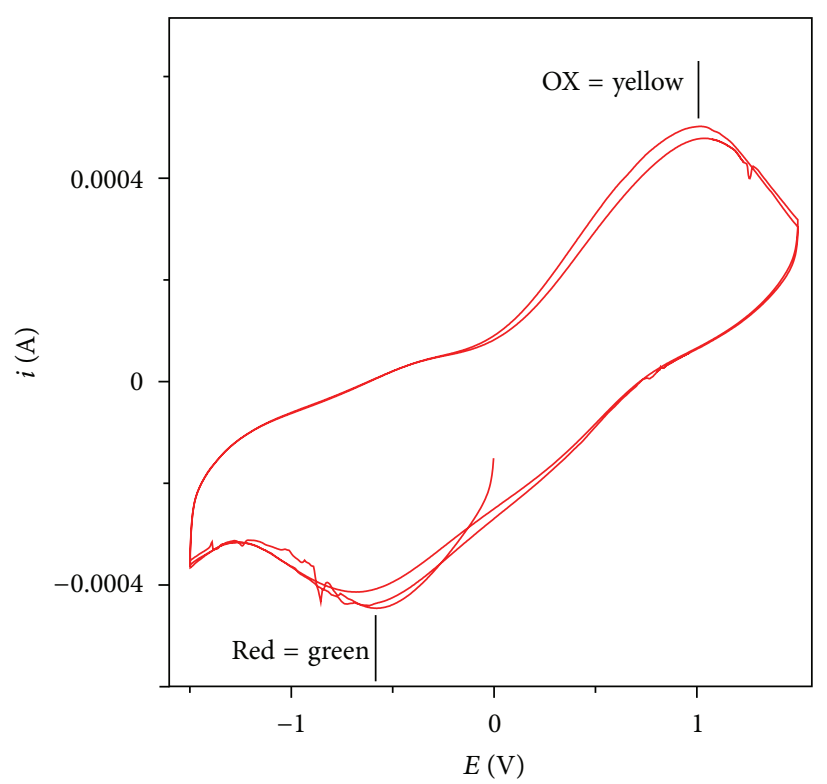

(b)

Figure 1: Typical CV of oxide films deposited on ITO prepared in this work. (a) $\mathrm{WO}_{3} / \mathrm{ITO}$ cathode in $\mathrm{LiNO}_{3} 0.1 \mathrm{M}$ aqueous solution. (b) $\mathrm{V}_{2} \mathrm{O}_{5} /$ ITO Anode in $\mathrm{LiNO}_{3} 0.1 \mathrm{M}$ ethanol solution. Electrodes configuration: ITO/Oxide film as working, $\mathrm{Pt}$ as counter, Sat. Ag/AgCl as reference. Scan rate $0.2 \mathrm{~V} / \mathrm{s}$. Color change is well visible by naked eye during scansion for both $\mathrm{WO}_{3}$ and $\mathrm{V}_{2} \mathrm{O}_{5}$. In the plots RED stands for reduced form and OX for oxidized form.

Ar 6.0, and also treated with molecular sieves (Molecular sieves, beads $4 \AA, 8-12$ mesh, Aldrich) to ensure the complete removal of traces of water/moisture from the liquid monomers. The polymer electrolyte membrane (PE) was prepared by mixing the monomer BEMA, PEGMA, LiTFSI, EC:DEC, and D1173 with a weight ratio: $20: 15: 20: 42: 3$, respectively. All the mixtures prepared were later poured on to the electrodes of EC devices and UV irradiated for $3 \mathrm{~min}$ under nitrogen atmosphere and these conditions assured a quantitative conversion. The photochemical curing was performed using a medium vapour pressure Hg lamp (Helios Italquartz, Italy), with a surface radiation intensity of $30 \mathrm{~mW} \mathrm{~cm}^{-2}$.

2.3. EC Device with Gel-Polymer Electrolyte Assembly. The EC devices (ECD) were assembled manually, by preparing the polymeric electrolyte formulation in dry-box and directly pouring it over the surface of one of the two electrodes. The second electrode was then placed on top of the electrolyte layer (still liquid) with the setup shown in Figure 2. In a typical device the $\mathrm{WO}_{3}$ and $\mathrm{V}_{2} \mathrm{O}_{5}$ films were deposited over a circular area of $18 \mathrm{~mm}$ diameter. The PET masks were used as spacers to tune the thickness polymeric electrolyte layer $(100 \mu \mathrm{m})$. The device was then positioned under the UV lamp for the photo-polymerization for approximately $3 \mathrm{~min}$ as described in the previous section. These conditions assured maximum curing (disappearance of the double bonds in methacrylic units, as checked by FT-IR). After curing, it was observed that the two electrodes were well glued by Polymeric Electrolyte (PE) and the ECD was intact.

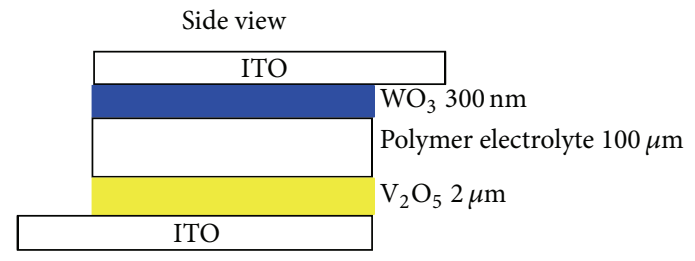

Top view

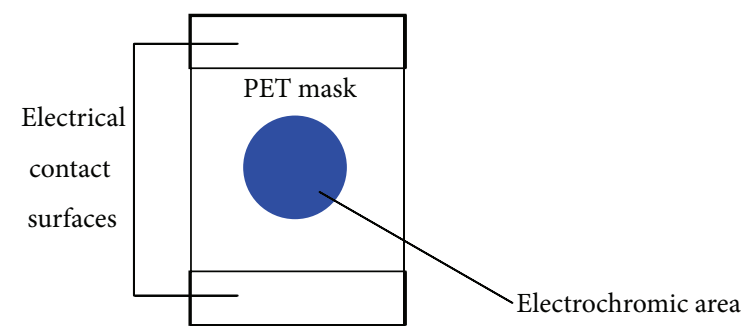

FIGURE 2: Schematic illustration of ECD prepared in this work.

2.4. Characterization Techniques. CH Instrument $600 \mathrm{D}$ Station (galvanostat/potentiostat, CHI instruments, Austin, USA) was used for electrochemical measurements and to operate the Electrochromic Devices, by registering current versus potential and current versus time curves. AC impedance spectroscopy was employed to investigate the ionic conductivity of the polymeric membrane [21]; frequency range was $100 \mathrm{kHz}-1 \mathrm{~Hz}$ with a three electrode testing cell made of stainless steel (SS) electrodes having the configuration: SS/PE/SS. Spectroelectrochemical measurements 
were carried out by placing the ECD in the sample compartment of a Varian Cary 500 UV-VIS spectrophotometer. Two different types of measurement were performed by coupling the spectrophotometer with the $\mathrm{CH} 600 \mathrm{D}$ potentiostat. The first type of experiment was the registration of the ECD complete UV-VIS absorption spectrum as function of applied potential; the second type of experiment consisted in the acquisition of the ECD absorption at a specific wavelength as function of time during potential modulation, that is, repeated bleaching and coloring cycles. The wavelength selected was that showing maximum $\Delta T \%$ in the corresponding full spectrum measurement. By the second type of measurement, the switching time and time stability of the ECD in bleached and colored state at open circuit condition were monitored.

Morphological characterization of the samples of $\mathrm{V}_{2} \mathrm{O}_{5}$ and estimation of the thickness of deposited layer was performed employing a FEI Quanta Inspect 200LV scanning electron microscope (SEM, max magnification of $1.5 \times 105$ ) equipped with an Everhardt Thornley secondary electron detector (ET-SED). Prior to the analysis, all the samples were coated with a thin $\mathrm{Cr}$ layer (around $10 \mathrm{~nm}$ thick) to minimize the effect of the electron beam irradiation.

Fourier Transform Infrared spectroscopy of electrodeposited $\mathrm{V}_{2} \mathrm{O}_{5}$ film has been performed by a Agilent Cary FTIR 630 equipped with a Glazing Angle sample holder.

Morphological characterization of the samples of $\mathrm{WO}_{3}$ and estimation of the thickness of deposited layer were obtained with a Zeiss Auriga SEM-FIB operated with an acceleration voltage of $2 \mathrm{kV}$ and aperture size of $30 \mu \mathrm{m}$, using secondary electrons image.

XRD diffraction pattern of the $\mathrm{WO}_{3}$ film was obtained by Bragg-Brentano geometry with $\mathrm{Cu} K \alpha$ line radiation $(\lambda=$ $1.5406 \AA$ ), in a PANalytical equipment, model X’Pert Pro.

\section{Results and Discussion}

3.1. Polymer Electrolyte Membrane. The switching time and the safety of EC devices is strongly influenced by the electrolyte and its ionic conductivity. In the present work, we developed an optimized gel polymer electrolyte membrane which can work at the same time as separator, electrolyte, and glue keeping the EC device together (see Figure 2). A polymer-based electrolyte similar to that chosen for this work was previously developed for the application in Li-ion cells $[16,21,22]$. The same knowledge and experience were used to study the feasibility of such materials to obtain reliable ECDs with reduced switching times. The ionic conductivity of BEMA/PEGMA based membranes prepared with certain percentage of LiTFSI dissolved in the EC-DEC $(1: 1 \mathrm{w} / \mathrm{w})$ solution (see Section 2.2) was evaluated by impedance spectroscopy and the Arrhenius plot is reported as Figure 3. The membrane showed a ionic conductivity of $1 \cdot 10^{-3} \mathrm{~S} \mathrm{~cm}^{-1}$ at room temperature and it was increased with temperature to obtain a value of $4 \cdot 10^{-3} \mathrm{~S} \mathrm{~cm}^{-1}$ at $80^{\circ} \mathrm{C}$.

The addition of different amounts of PEGMA as a reactive diluent helped to increase the ionic conductivity, in fact it can control the cross-linking density during the polymerization

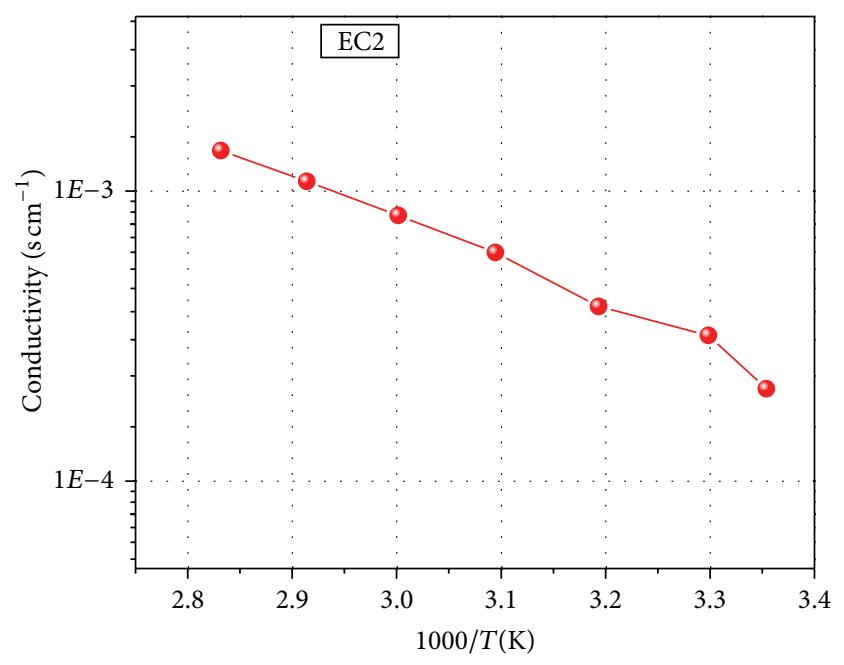

FIGURE 3: Ionic conductivity of BEMA/PEGMA polymer electrolyte versus temperature.

reaction; moreover, the pendant ethylene oxide groups can help the mobility of $\mathrm{Li}^{+}$ions through the matrix. Thus the resulting polymer was soft and the conductivity values were higher and even close to that of the common liquid electrolytes used in the field of lithium batteries. This electrolyte was selected considering its extended electrochemical stability [23], and the absence of decomposition between in the potential range of 0 to $4.6 \mathrm{~V}$ versus $\mathrm{Li}^{+} / \mathrm{Li}$.

3.2. EC Electrodes and Cell. $\mathrm{V}_{2} \mathrm{O}_{5}$ and $\mathrm{WO}_{3}$ were chosen as electrode materials, and the oxide films deposited over the ITO substrate looked very homogeneous. Electrodeposited $\mathrm{V}_{2} \mathrm{O}_{5}$ (Figure 4(a)) was yellow in the oxidized form and easily changed to green/grey in the reduced form. Sputtered $\mathrm{WO}_{3}$ (Figure 4(b)) was colourless in the oxidized form and bluish in the reduced form.

3.3. Electrochemical Measurements. First, a single electrode electrochromic device with $\mathrm{WO}_{3} / \mathrm{ITO} / \mathrm{PET}$ (working electrode) as cathode and ITO/PET as anode (counter and reference electrode) was tested; the device coloured and bleached state are shown in Figure 5.

To evaluate the switching time of the EC device, a double potential step chronoamperometric experiment was performed $\left(E_{1}=-2.0 \mathrm{~V}, E_{2}=+2.0 \mathrm{~V}\right.$ versus $\mathrm{V}_{2} \mathrm{O}_{5}$ electrode; $\left.t_{1}=t_{2}=10 \mathrm{~s}\right)$. The typical current versus time profile for a single-EC-electrode device is shown in Figure 6. In agreement with the literature $[1,4,5]$, the electrochemical insertion of lithium cations into $\mathrm{WO}_{3}$ occurs in the selected potential range according to the following reaction:

$$
\mathrm{WO}_{3} \text { (colorless) }+x \mathrm{Li}^{+}+x \mathrm{e}^{-} \longleftrightarrow \mathrm{Li}_{x} \mathrm{WO}_{3} \text { (blue) }
$$

The reaction described in the equation takes place at potentials of $-2 \mathrm{~V}$ versus $\mathrm{Li}$ [24]. The current versus time profile confirmed that the colouring/bleaching processes during the repeated potential cycling were reproducible and reversible (Figure 6). Moreover, the switching time of the 


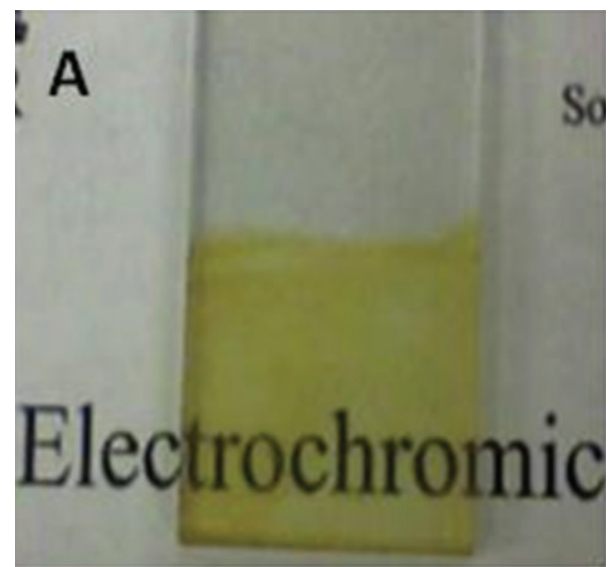

(a)

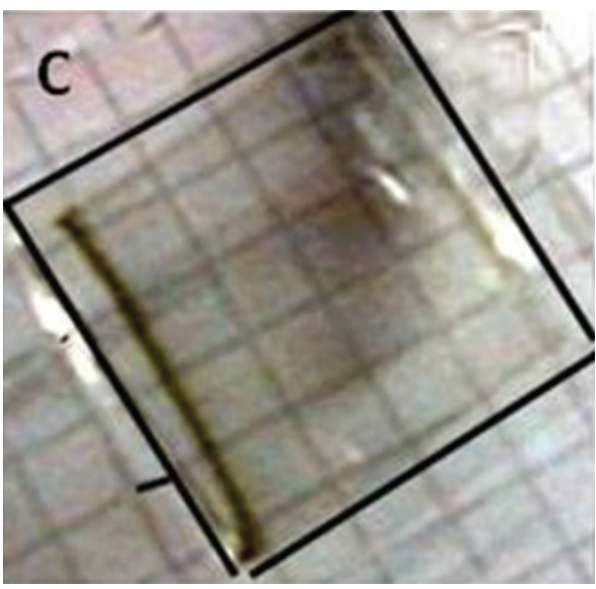

(c)

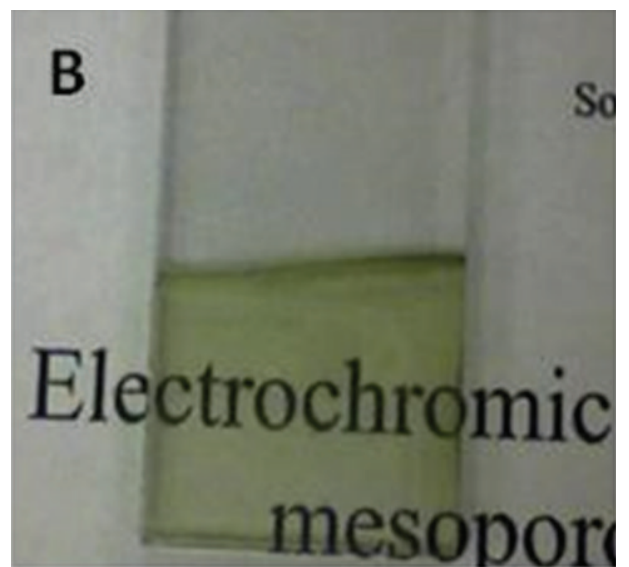

(b)

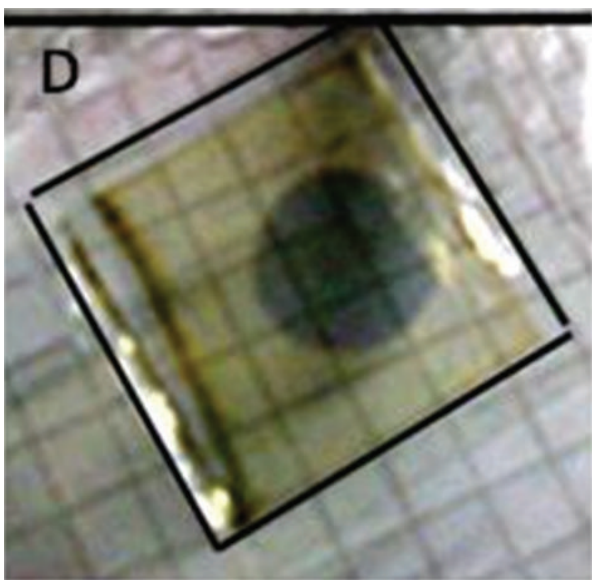

(d)

FIGURE 4: Electrodes appearance in electrochromic devices. (a) electrodeposited $\mathrm{V}_{2} \mathrm{O}_{5}$ on glass/ITO in the oxidized and (b) reduced form; (c) and (d) are respectively the bleached and coloured forms of the complete cell with sputtered $\mathrm{WO}_{3}$ on ITO coated glass (cathode, working electrode) and $\mathrm{V}_{2} \mathrm{O}_{5}$ on PET/ITO (anode, counter, and reference electrode).

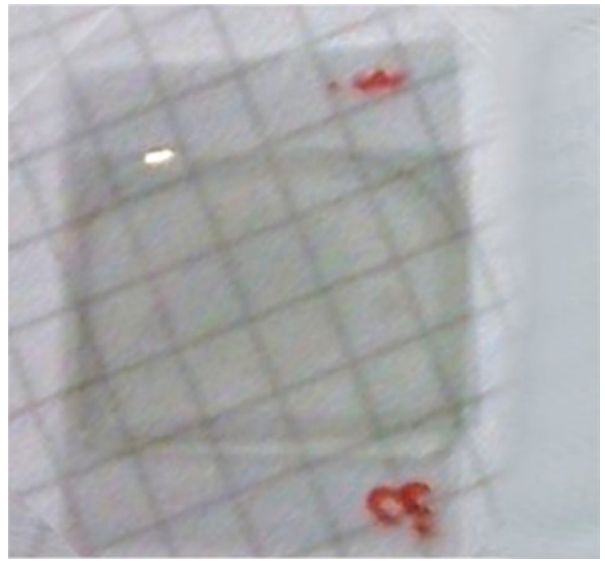

(a)

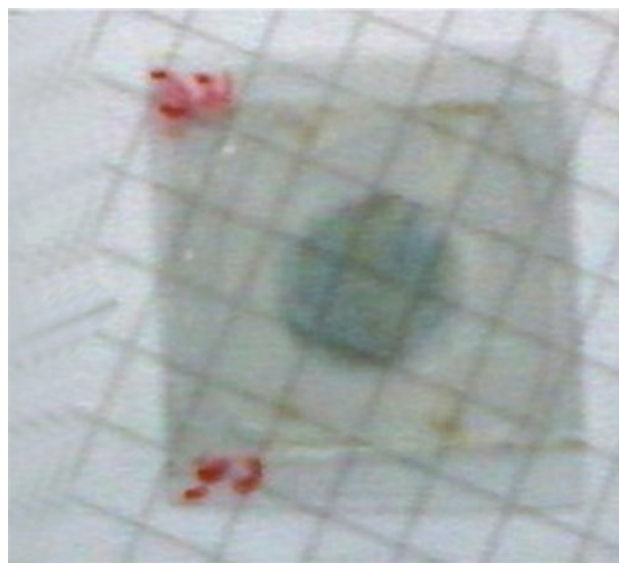

(b)

Figure 5: Single electrode EC device with BEMA/PEGMA electrolyte in bleached (a) and coloured state (b). Electrodes configuration: $\mathrm{WO}_{3} / \mathrm{ITO} / \mathrm{PET}$ as cathode and ITO/PET as anode and reference electrode. 


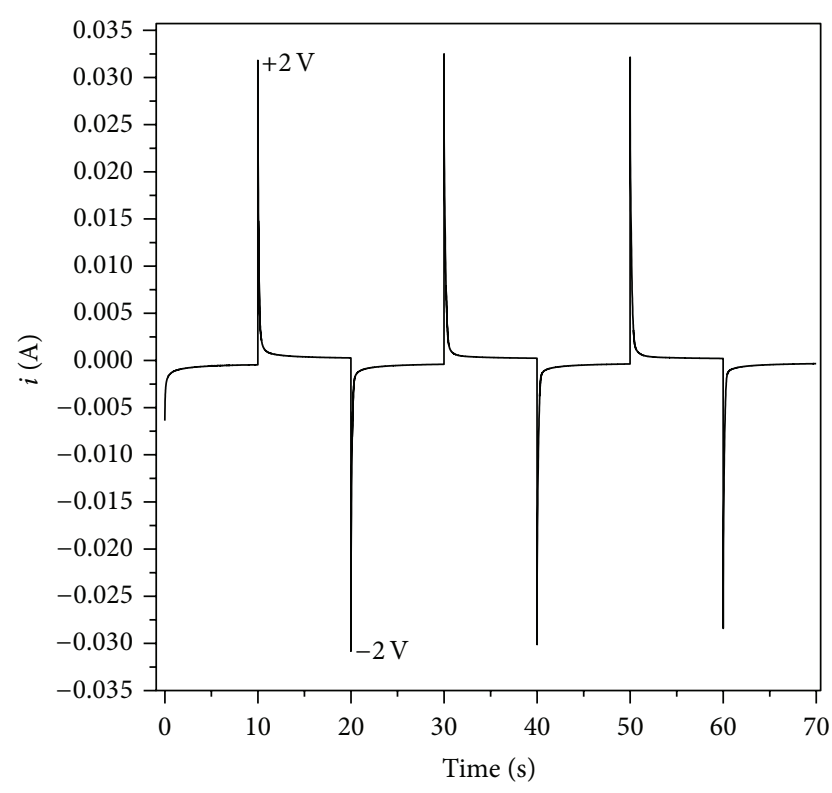

FIgure 6: Chronoamperometric profile of a $\mathrm{WO}_{3} / \mathrm{PE} / \mathrm{ITO} \mathrm{ECD}$ device. Electrodes configuration: $\mathrm{WO}_{3} / \mathrm{ITO} /$ Glass as working and ITO/PET as counter and reference electrode. $E_{1}=-2.0 \mathrm{~V}, E_{2}=$ $+2.0 \mathrm{~V}$ versus ITO electrode. $t_{1}=t_{2}=10 \mathrm{~s}$.

device, estimated by the method described in the following section was found to be of ca. $2 \mathrm{~s}$ for the colouring $\left(\mathbf{S T}_{\mathbf{C}}\right)$ and about $1 \mathrm{~s}$ for the bleaching process $\left(\mathbf{S T}_{\mathbf{B}}\right)$. Successively, a complete cell was assembled using the $\mathrm{WO}_{3}$ thin film sputtered on ITO as cathode and the $\mathrm{V}_{2} \mathrm{O}_{5}$ layer electrodeposited on ITO as anode. The results of chronoamperometric measurements are shown in Figure 7.

The reaction occurring at the cathode corresponds to the one reported in the previous equation. When the electrochemical reduction of $\mathrm{WO}_{3}$ occurs at the cathode, the oxidation of $\mathrm{V}_{2} \mathrm{O}_{5}$ takes place at the anode. Considering that the electrochemical deposition of $\mathrm{V}_{2} \mathrm{O}_{5}$ carried out in galvanostatic conditions lead to the formation of mixed oxides, a certain percentage of $\mathrm{V}$ oxides in lower oxidation state (IV and III) is always present by making the ECD electrochemically switchable by oxidation from the first cycle of potential application [23]. The electrochemical switching time of complete cell was found identical to that of single electrode, that is, $\mathbf{S T}_{\mathbf{C}}=2 \mathrm{~s}$ and $\mathbf{S T}_{\mathbf{B}}=1 \mathrm{~s}$. Such values for colouring and bleaching processes are a clear enhancement with respect to those reported previously for similar systems [11, $25,26]$. As representative example an electrochromic device containing methacrylate-based gel polymer electrolytes (PE) was reported by Reiter et al. [11]. These devices were all glass $\left(\mathrm{WO}_{3} / \mathrm{ITO}\right) / \mathrm{PE} /\left(\mathrm{V}_{2} \mathrm{O}_{5} / \mathrm{ITO}\right)$ and showed a switching time of ca. $20 \mathrm{~s}$. By considering this value, the improved switching times we have obtained can be ascribed to the optimized formulation of the polymeric electrolyte granting faster $\mathrm{Li}^{+}$ migration between cathode and anode.

3.4. Electro-Optical Measurements. Spectroelectrochemical measurements where performed on freshly prepared ECD

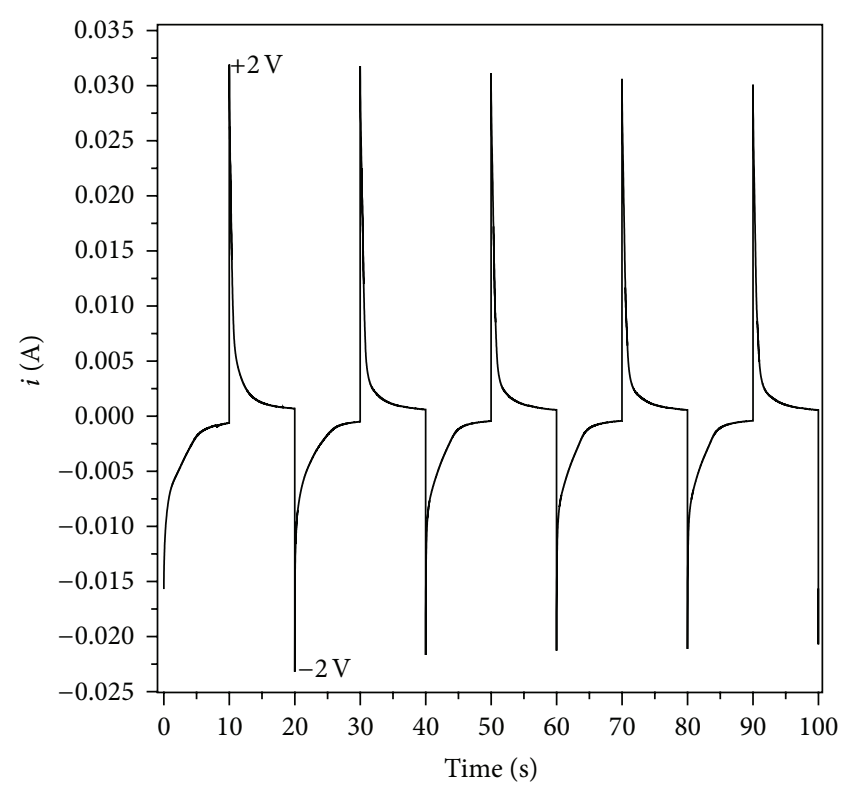

FIGURE 7: Chronoamperometric profile of a $\mathrm{WO}_{3} / \mathrm{PE} / \mathrm{V}_{2} \mathrm{O}_{5} \mathrm{ECD}$. Electrodes configuration: $\mathrm{WO}_{3} / \mathrm{ITO} /$ Glass as working electrode and $\mathrm{V}_{2} \mathrm{O}_{5} / \mathrm{ITO} / \mathrm{PET}$ as counter and reference electrode. $E_{1}=-2.0 \mathrm{~V}$, $E_{2}=+2.0 \mathrm{~V}$ versus $\mathrm{V}_{2} \mathrm{O}_{5}$ electrode. $t_{1}=t_{2}=10 \mathrm{~s}$.

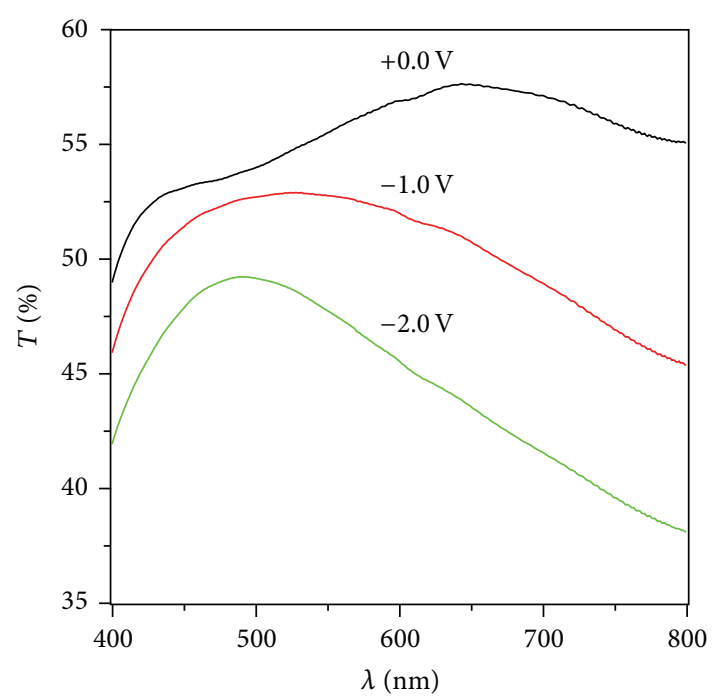

FIGURE 8: UV-VIS transmittance spectra of a complete cell containing $\mathrm{V}_{2} \mathrm{O}_{5}$ and $\mathrm{WO}_{3}$ films registered at $0,-1$, and $-2 \mathrm{~V}$ versus $\mathrm{V}_{2} \mathrm{O}_{5}$ electrode.

with the configuration $\mathrm{WO}_{3} / \mathrm{PE} / \mathrm{V}_{2} \mathrm{O}_{5}$. The corresponding UV-VIS transmittance spectrum at different applied potentials is reported in Figure 8. The UV-VIS spectrum was recorded at potentials ranging from $0 \mathrm{~V}$ to $-2 \mathrm{~V}$ (versus $\mathrm{V}_{2} \mathrm{O}_{5}$ electrode); the selected potential was applied continuously for $60 \mathrm{~s}$ before data collection. The transmittance spectrum in $500-800 \mathrm{~nm}$ region clearly demonstrated the capability of the EC cells to progressively change colour with variable negative potentials. The change in colour was already detectable at $-1 \mathrm{~V}$, and at $-2 \mathrm{~V}$ a complete colour change was observed 


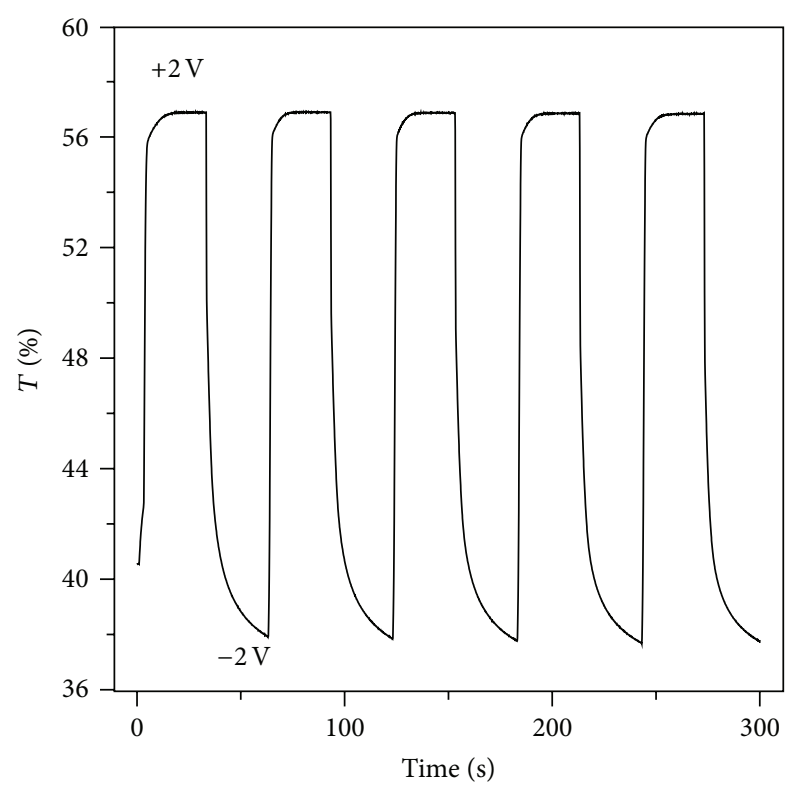

FIgURE 9: Time plot of UV-VIS transmittance at $700 \mathrm{~nm}$ during repeated switching between bleached and coloured state for a $\mathrm{WO}_{3} / \mathrm{PE} / \mathrm{V}_{2} \mathrm{O}_{5} \mathrm{ECD}$. Electrodes configuration: $\mathrm{WO}_{3} / \mathrm{ITO} /$ Glass as cathode and $\mathrm{V}_{2} \mathrm{O}_{5} / \mathrm{ITO} / \mathrm{PET}$ as anode. Potential program: $E_{1}=$ $+2 \mathrm{~V} ; E_{2}=-2 \mathrm{~V}$ (versus $\mathrm{V}_{2} \mathrm{O}_{5}$ electrode); $t_{1}=t_{2}=30 \mathrm{~s}$.

in less than $4 \mathrm{~s}$. The highest sensitivity for human eyes is at $550 \mathrm{~nm}$, and at this wavelength, the contrast between bleached and colored state is $\Delta \mathrm{T} \%_{(\mathbf{5 5 0} \mathbf{~ n m})}=7.5$. But, the performance of the EC cell is interesting if we consider the complete visible region $(380-800 \mathrm{~nm}$ ) and the prospects of the application of polymer electrolytes for the realization of a completely solid and flexible room temperature EC display. The maximum colour change is detected at wavelengths higher than $700 \mathrm{~nm}\left(\Delta \mathrm{T} \%_{(700 \mathrm{~nm})}=16.5\right.$; $\left.\Delta \mathrm{T} \%_{(\mathbf{8 0 0} \mathbf{n m})}=20\right)$. Considering the $\mathrm{V}_{2} \mathrm{O}_{5}$-based anodes the contrast of ECD could be further improved by introducing prelithiated electrochromic materials increasing the density of ion insertion sites and thus the number of chromophores. As already stated, especially for electronic applications, the decrease in switching time and the enhancement of the cycling stability are the most significant challenges. In order to evaluate the switching time, successive steps of negative and positive potentials were applied to the device for several cycles $\left(E_{1}=-2 \mathrm{~V}, E_{2}=+2 \mathrm{~V}\right)$. In this work $\mathbf{S T}_{\mathbf{B}}$ is defined as the time necessary to the ECD to reach the $60 \%$ of the maximum contrast $\left(\Delta \mathrm{T} \%_{\max }\right)$ from the application of the positive potential step. On the other side, $\mathbf{S T}_{\mathbf{C}}$ is defined as the time necessary to the ECD to reach the $60 \%$ of the maximum contrast $\left(\Delta \mathrm{T} \%_{\max }\right)$ from the application of the negative potential step. Figure 9 displays the transmittance of the device with configuration $\mathrm{WO}_{3} / \mathrm{PE} / \mathrm{V}_{2} \mathrm{O}_{5}$ at $700 \mathrm{~nm}$, when the voltage is changed according to the potential program described in the caption. The light transmittance is very stable during cycling even after several consecutive cycles. As the de-insertion process in $\mathrm{WO}_{3}$ is faster than the insertion process; thus, the bleaching process is faster than

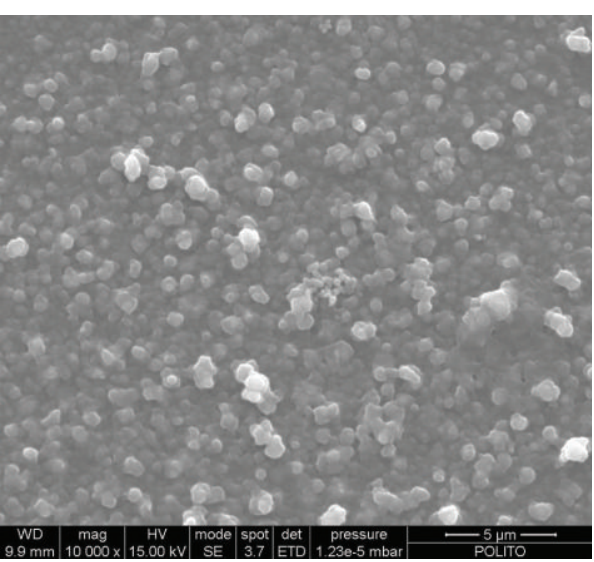

(a)

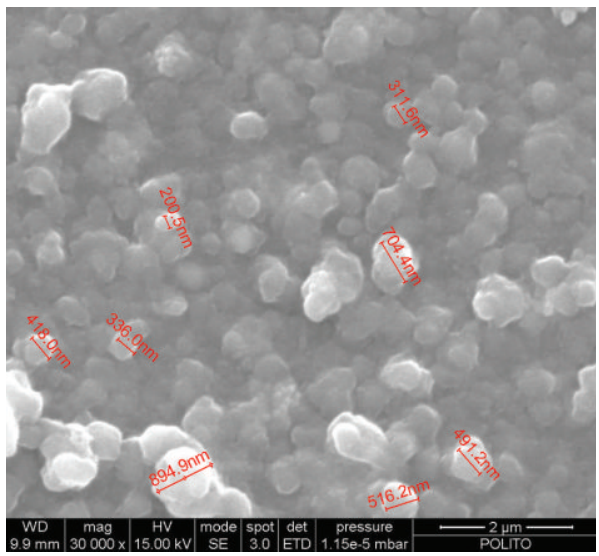

(b)

FIGURE 10: SEM pictures showing the high homogeneity and microporosity of $\mathrm{V}_{2} \mathrm{O}_{5}$ film electrodeposited on ITO.

the colouring process, then $\mathbf{S T}_{\mathbf{C}}=2 \mathrm{~s}$ and $\mathbf{S T}_{\mathbf{B}}=1 \mathrm{~s}$. The difference between switching time of coloring $\mathbf{S T}_{\mathbf{C}}=2 \mathrm{~s}$ and switching time of bleaching $\mathbf{S T}_{\mathbf{B}}=1 \mathrm{~s}$ is due to oxide film surface charge. In general, the rate of $\mathrm{Li}^{+}$intercalation is higher in $\mathrm{WO}_{3}$ with respect to $\mathrm{V}_{2} \mathrm{O}_{5}$ then the "bottle neck", that is, the electrode determining the device switching time is the $\mathrm{V}_{2} \mathrm{O}_{5}$ anode [7-10]. $\mathrm{V}_{2} \mathrm{O}_{5}$-based anodes prepared here, as confirmed by SEM images, are very homogeneous and micro-porous granting good counter electrode performances (Figure 10). In fact $\mathbf{S} \mathbf{T}_{\mathbf{B}}$ is quite similar to $\mathbf{S} \mathbf{T}_{\mathbf{C}}$. Considering theECD assembled in this work when $\mathrm{WO}_{3}$ (see Figures 12 and 13 for typical XRD pattern and SEM morphology of the film) is reduced (coloring) $\mathrm{V}_{2} \mathrm{O}_{5}$ is oxidized (bleaching) then the slower step is most likely the $\mathrm{Li}^{+}$de-intercalation from $\mathrm{V}_{2} \mathrm{O}_{5}$; this seems to indicate that the surface change of $\mathrm{V}_{2} \mathrm{O}_{5}$ is negative and there is an attractive electrostatic field versus $\mathrm{Li}^{+}$that promote $\mathrm{Li}^{+}$insertion and partially prevents $\mathrm{Li}^{+}$de-insertion from $\mathrm{V}_{2} \mathrm{O}_{5}$ layer. To confirm the presence of $-\mathrm{OH}$ groups on the surface of $\mathrm{V}_{2} \mathrm{O}_{5}$ possibly causing negative charges on the oxide surface FTIR spectrum has been registered (Figure 11). The FTIR spectrum clearly evidences the presence of different types of oxydrilic group on the $\mathrm{V}_{2} \mathrm{O}_{5}$ layer. It is well known that EC devices change colour 


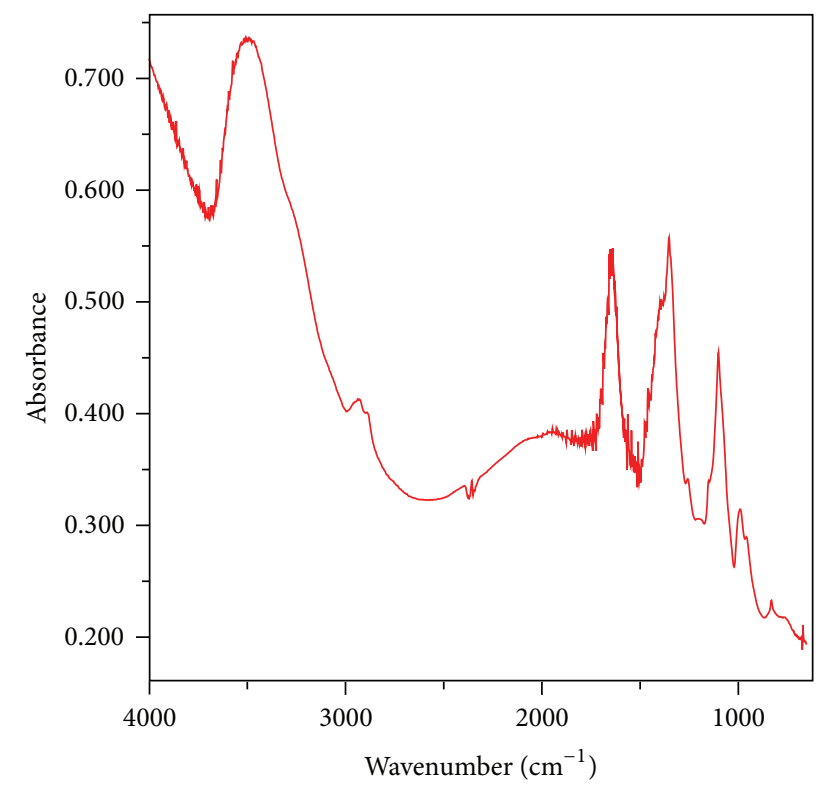

FIGURE 11: FTIR spectrum of $\mathrm{V}_{2} \mathrm{O}_{5}$ film electrodeposited on ITO.

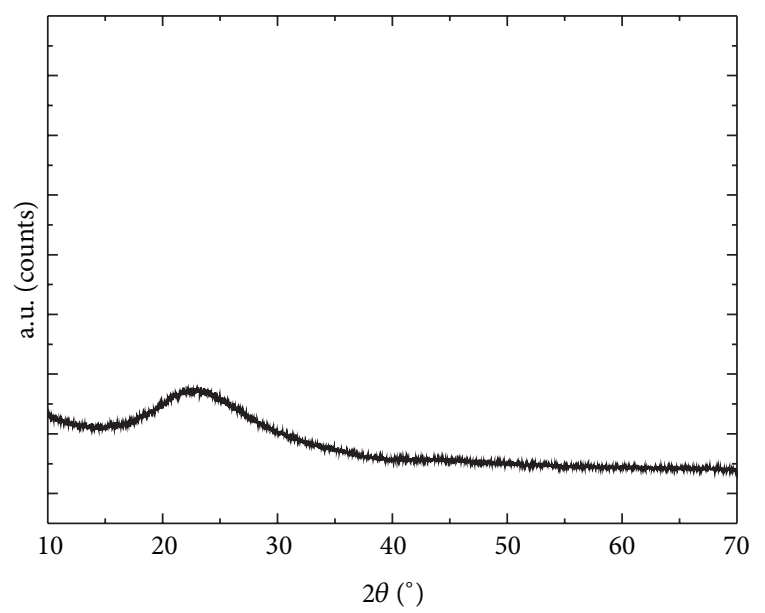

Figure 12: Typical X Ray diffraction pattern of the sputtered $\mathrm{WO}_{3}$ film.

in a reversible but permanent way and this feature enables us to avoid continuous energy consumption; however, to ensure energy saving, the colour change must be stable even at open circuit conditions, that, is in absence of biasing. To check the stability of the coloured state, light transmittance of the complete device was monitored at $700 \mathrm{~nm}$ by applying $-2 \mathrm{~V}$ versus $\mathrm{V}_{2} \mathrm{O}_{5}$ for 10 seconds, and successively keeping the EC cell at open circuit conditions. The test demonstrated that the coloured state was pretty stable and permanent at open circuit, as shown in Figure 14(b). The same effect was also detectable when a potential of $+2 \mathrm{~V}$ versus $\mathrm{V}_{2} \mathrm{O}_{5}$ was applied and followed by open circuit conditions (Figure 14(a)); the graph clearly show that the bleached state was very stable.

A basic study of the $\mathrm{WO}_{3} / \mathrm{PE} / \mathrm{V}_{2} \mathrm{O}_{5}$ ECD lifetime has been performed. The ECD has been electrochemically switched for 1000 cycles and the values of switching time

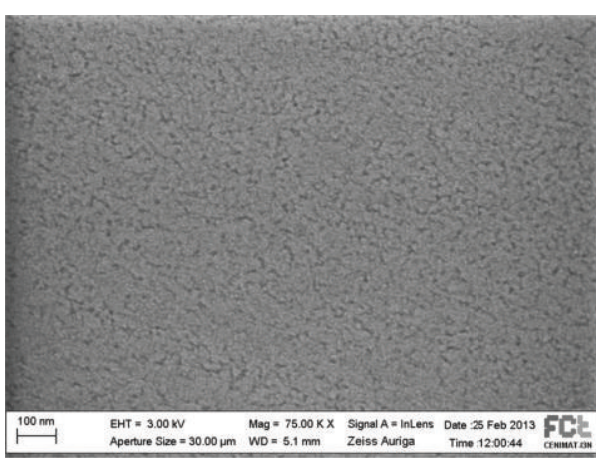

FIGURE 13: A representative SEM image of the $\mathrm{WO}_{3}$ film showing the high homogeneity of the deposit at nanoscale level.

TABLE 1: Effect of 10000 cycles of electrochemical switching on $\mathrm{ST}_{\mathrm{B}}, \mathrm{ST}_{\mathrm{C}}$, and $\Delta \mathrm{T} \%_{(700 \mathrm{~nm})}$ of a typical ECD with the configuration $\mathrm{WO}_{3} / \mathrm{PE} / \mathrm{V}_{2} \mathrm{O}_{5}$. Each cycle is made of $20 \mathrm{~s}$ at $+2 \mathrm{~V}$ (bleaching) and $20 \mathrm{~s}$ at $-2 \mathrm{~V}$ (coloring). Potentials are versus $\mathrm{V}_{2} \mathrm{O}_{5}$ anode acting as counter and reference electrode.

\begin{tabular}{lcc}
\hline & Cycle nr. 5 & Cycle nr. 1000 \\
\hline $\mathbf{S T}_{\mathbf{B}}$ & $1 \mathrm{~s}$ & $1.6 \mathrm{~s}$ \\
$\mathbf{S T}_{\mathrm{C}}$ & $2 \mathrm{~s}$ & $2.9 \mathrm{~s}$ \\
$\Delta \mathbf{T}_{(\mathbf{7 0 0} \mathbf{n m})}$ & 16.5 & 9.3 \\
\hline
\end{tabular}

and contrast $\left(\mathbf{S T}_{\mathbf{B}}, \mathbf{S T}_{\mathrm{C}}, \Delta \mathrm{T} \%_{(\mathbf{7 0 0} \mathrm{nm})}\right)$ have been compared in Table 1 at cycle nr. 5 and cycle nr. 1000. Each cycle was made of $20 \mathrm{~s}$ at $+2 \mathrm{~V}$ (bleaching) and $20 \mathrm{~s}$ at $-2 \mathrm{~V}$ (coloring). The results show that ECD is still responsive after 1000 cycles,

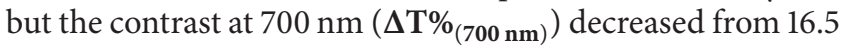
to 9.3 indicating that ca. $30 \%$ of $\mathrm{WO}_{3}$ centers are no more active. A probable reason is the presence of little amounts of water in EC/DEC solvent developing bobbles of $\mathrm{H}_{2}$ and $\mathrm{O}_{2}$ that can partially detach polymer electrolyte from $\mathrm{WO}_{3}$ thin layer or the oxide thin film itself. This effect is slow but it is fundamental for the ECD lifetime. The switching times of coloring and bleaching are also affected after 1000 cycles and their values increased of ca. $50 \%$ due to the slow evaporation of EC/DEC solvent which causes a progressive decrease of $\mathrm{Li}^{+}$mobility affecting thus the ECD responsivity. To limitate this effect and to extend the effective device lifetime, it is fundamental to improve the encapsulation of the device to slow down solvent evaporation and avoid the contamination with $\mathrm{O}_{2}$ and $\mathrm{H}_{2} \mathrm{O}$ from atmosphere.

\section{Conclusion}

A quasi solid state complete electrochromic device was successfully realised for the first time with an optimized BEMA/PEGMA-based gel polymer electrolyte bridging a sputtered $\mathrm{WO}_{3}$ cathode and a electrodeposited $\mathrm{V}_{2} \mathrm{O}_{5}$ anode. Rigid all glass or flexible ITO/PET ECDs can be easily prepared with the same deposition methods and structure. The ECD exhibited a switching time for bleaching of ca. $1 \mathrm{~s}$ and a switching time of coloring of ca. $2 \mathrm{~s}$ which is considerably faster of the values previously reported for similar polymeric devices. The ECD showed also good color 


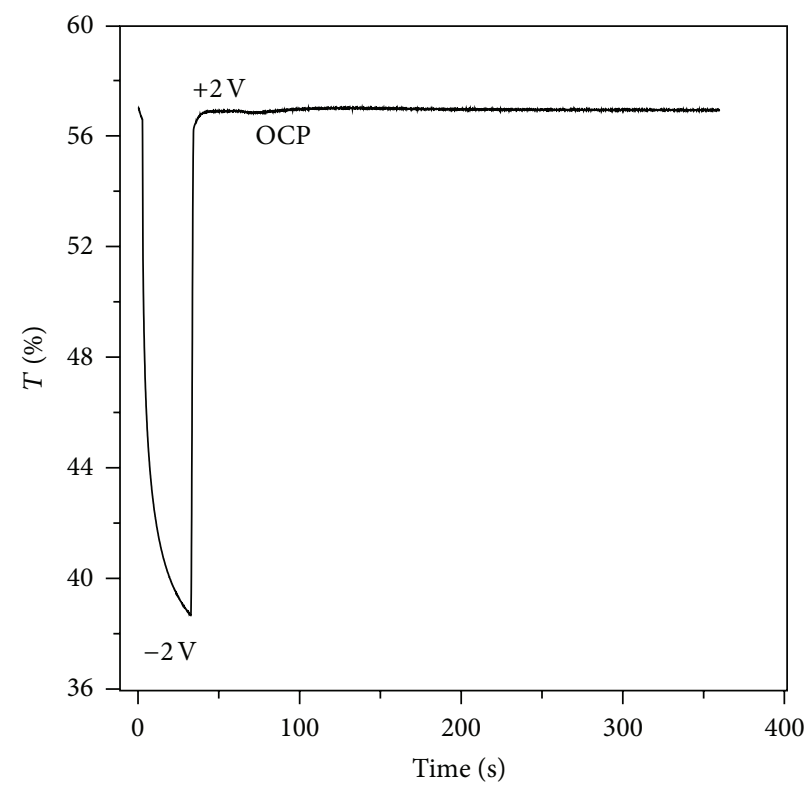

(a)

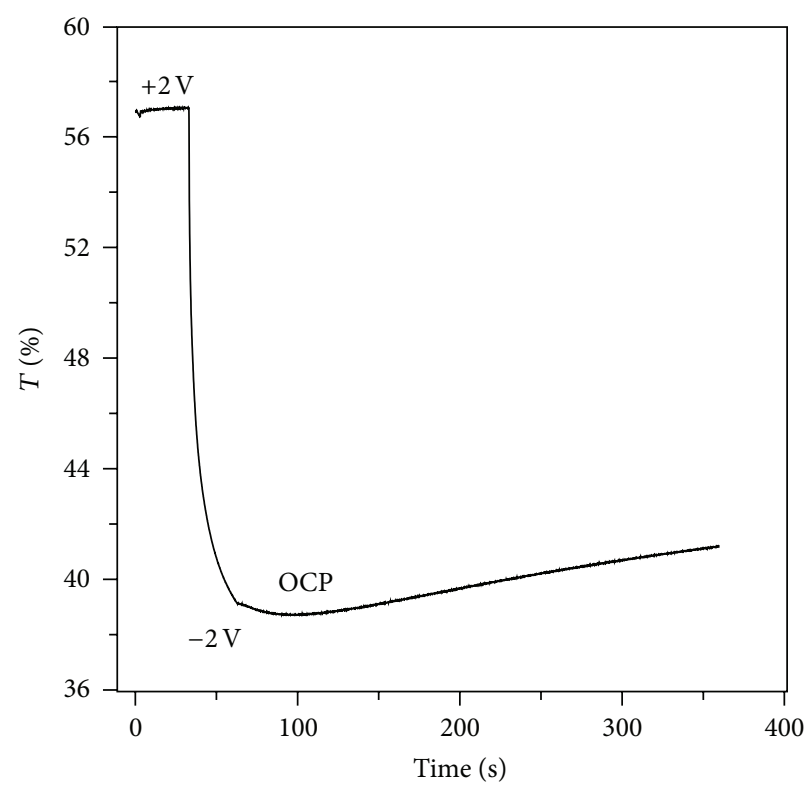

(b)

FIgURE 14: Time stability UV-VIS Transmittance measurements at open circuit and fixed wavelength $(700 \mathrm{~nm}) \mathrm{for}_{\mathrm{a} \mathrm{WO}} / \mathrm{PE} / \mathrm{V}_{2} \mathrm{O}_{5} \mathrm{ECD}$. Electrodes configuration: $\mathrm{WO}_{3} / \mathrm{ITO} /$ Glass as cathode and $\mathrm{V}_{2} \mathrm{O}_{5} / \mathrm{ITO} / \mathrm{PET}$ as anode. (a) bleached state $\left(E=+2 \mathrm{~V}\right.$ versus $\mathrm{V}_{2} \mathrm{O}_{5}$ for $\left.10 \mathrm{~s}\right)$; (b) coloured state $\left(E=-2 \mathrm{~V}\right.$ versus $\mathrm{V}_{2} \mathrm{O}_{5}$ for $\left.10 \mathrm{~s}\right)$.

retention characteristics at open circuit conditions. The polymeric electrolytes employed has demonstrated good ionic conductivity, wide electrochemical stability, and appears to be interesting candidates as electrolytes for thin and flexible displays. A basic study of the $\mathrm{WO}_{3} / \mathrm{PE} / \mathrm{V}_{2} \mathrm{O}_{5} \mathrm{ECD}$ lifetime show that the devices are still operative and responsive after 1000 cycles of electrochemical switching. Work is in progress to further improve the switching time and contrast by enhancing the polymer-based electrolyte and introducing Li preintercalated oxide films as anode materials.

\section{Acknowledgments}

EU community is gratefully acknowledged for funding SMARTEC (Heterogeneous integration of autonomous smart films based on electrochromic transistors) Grant Agreement number: 258203. The authors would like to acknowledge PEst-C/CTM/LA0025/2013-14 (Strategic Project-LA25-20132014) for the support given to CENIMAT/I3N.

\section{References}

[1] C. G. Granqvist, Handbook of Inorganic Electrochromic Materials, Elsevier, Amsterdam, The Netherlands, 2002.

[2] J. Fusong, Z. Tao, and Y. Yong, "Preparation and electrochromic properties of tungsten oxide and iridium oxide porous films," Journal of Non-Crystalline Solids, vol. 354, no. 12-13, pp. 12901293, 2008.

[3] Y. Suda, H. Kawasaki, T. Ohshima, and Y. Yagyuu, "Characteristics of tungsten oxide thin films prepared on the flexible substrates using pulsed laser deposition," Thin Solid Films, vol. 516, no. 13, pp. 4397-4401, 2008.
[4] S. K. Deb, "Opportunities and challenges in science and technology of $\mathrm{WO}_{3}$ for electrochromic and related applications," Solar Energy Materials and Solar Cells, vol. 92, no. 2, pp. 245258, 2008.

[5] M. Deepa, M. Kar, D. P. Singh, A. K. Srivastava, and S. Ahmad, "Influence of polyethylene glycol template on microstructure and electrochromic properties of tungsten oxide," Solar Energy Materials and Solar Cells, vol. 92, no. 2, pp. 170-178, 2008.

[6] A. Georg, W. Graf, and V. Wittwer, "Switchable windows with tungsten oxide," Vacuum, vol. 82, no. 7, pp. 730-735, 2008.

[7] S. Beke, "A review of the growth of $\mathrm{V}_{2} \mathrm{O}_{5}$ films from 1885 to 2010," Thin Solid Films, vol. 519, no. 6, pp. 1761-1771, 2011.

[8] A. Kumar, P. Singh, N. Kulkarni, and D. Kaur, "Structural and optical studies of nanocrystalline V2O5 thin films," Thin Solid Films, vol. 516, no. 6, pp. 912-918, 2008.

[9] Y.-S. Lin, C.-W. Tsai, and P.-W. Chen, "Electrochromic properties of $\mathrm{V}_{2} \mathrm{O}_{5}-\mathrm{Z}$ thin films sputtered onto flexible PET/ITO substrates," Solid State Ionics, vol. 179, no. 7-8, pp. 290-297, 2008.

[10] P. Liu, S.-H. Lee, C. Edwin Tracy, J. A. Turner, J. R. Pitts, and S. K. Deb, "Electrochromic and chemochromic performance of mesoporous thin-film vanadium oxide," Solid State Ionics, vol. 165, no. 1-4, pp. 223-228, 2003.

[11] J. Reiter, O. Krejza, and M. Sedlaříková, "Electrochromic devices employing methacrylate-based polymer electrolytes," Solar Energy Materials and Solar Cells, vol. 93, no. 2, pp. 249255, 2009.

[12] R. MacCallum and C. A. Vincent, Polymer Electrolyte Reviews, vol. 1-2, Elsevier, London, UK, 1989.

[13] C. Gerbaldi, J. R. Nair, S. Ahmad et al., "UV-cured polymer electrolytes encompassing hydrophobic room temperature ionic liquid for lithium batteries," Journal of Power Sources, vol. 195, no. 6, pp. 1706-1713, 2010. 
[14] C. Gerbaldi, "All-solid-state lithium-based polymer cells for high-temperature applications," Ionics, vol. 16, no. 9, pp. 777786, 2010.

[15] P. C. Barbosa, M. M. Silva, M. J. Smith, A. Gonçalves, and E. Fortunato, "Solid-state electrochromic devices based on poly(trimethylene carbonate) and lithium salts," Thin Solid Films, vol. 516, no. 7, pp. 1480-1483, 2008.

[16] J. R. Nair, C. Gerbaldi, G. Meligrana et al., "UV-cured methacrylic membranes as novel gel-polymer electrolyte for Liion batteries," Journal of Power Sources, vol. 178, no. 2, pp. 751757, 2008.

[17] P. C. Barbosa, M. M. Silva, M. J. Smith, A. Gonçalves, and E. Fortunato, "Studies of solid-state electrochromic devices based on $\mathrm{PEO} /$ siliceous hybrids doped with lithium perchlorate," Electrochimica Acta, vol. 52, no. 8, pp. 2938-2943, 2007.

[18] J. R. Nair, C. Gerbaldi, G. Meligrana, R. Bongiovanni, S. Bodoardo, and N. Penazzi, "Photo-curable siloxane-acrylates based gel copolymer electrolyte (GCE) For Li-ion battery application," in Europolymer Conference on Advanced Polymeric Materials for the Energy Resources Exploitation (EUPOC '08), Gargnano, Italy, June 2008.

[19] E. Zelazowska and E. Rysiakiewicz-Pasek, "WO3-based electrochromic system with hybrid organic-inorganic gel electrolytes," Journal of Non-Crystalline Solids, vol. 354, no. 35-39, pp. 4500-4505, 2008.

[20] B. Oh, W. Jung, D. W. Kim, and H. W. Rhee, "Preparation of UV curable gel polymer electrolytes and their electrochemical properties," Bulletin of the Korean Chemical Society, vol. 23, no. 5, pp. 683-687, 2002.

[21] J. R. Nair, C. Gerbaldi, M. Destro, R. Bongiovanni, and N. Penazzi, "Methacrylic-based solid polymer electrolyte membranes for lithium-based batteries by a rapid UV-curing process," Reactive and Functional Polymers, vol. 71, no. 4, pp. 409416, 2011.

[22] C. Gerbaldi, J. R. Nair, G. Meligrana, R. Bongiovanni, S. Bodoardo, and N. Penazzi, "Highly ionic conducting methacrylic-based gel-polymer electrolytes by UV-curing technique," Journal of Applied Electrochemistry, vol. 39, no. 11, pp. 2199-2207, 2009.

[23] E. Potiron, A. Le Gal La Salle, A. Verbaere, Y. Piffard, and D. Guyomard, "Electrochemically synthesized vanadium oxides as lithium insertion hosts," Electrochimica Acta, vol. 45, no. 1, pp. 197-214, 1999.

[24] L. Gracia, J. García-Cañadas, G. Garcia-Belmonte, A. Beltrán, J. Andrés, and J. Bisquert, "Composition dependence of the energy barrier for lithium diffusion in amorphous $\mathrm{WO}_{3}$," Electrochemical and Solid-State Letters, vol. 8, no. 10, pp. J21-J23, 2005.

[25] H.-S. Shima, J. W. Kima, Y.-E. Sung, and W. B. Kima, "Electrochromic properties of tungsten oxide nanowires fabricated by electrospinning method," Solar Energy Materials and Solar Cells, vol. 93, no. 12, pp. 2062-2068, 2009.

[26] J. Zhang, J. P. Tu, X. H. Xia, Y. Qiao, and Y. Lu, "An all-solidstate electrochromic device based on $\mathrm{NiO} / \mathrm{WO}_{3}$ complementary structure and solid hybrid polyelectrolyte," Solar Energy Materials and Solar Cells, vol. 93, no. 10, pp. 1840-1845, 2009. 

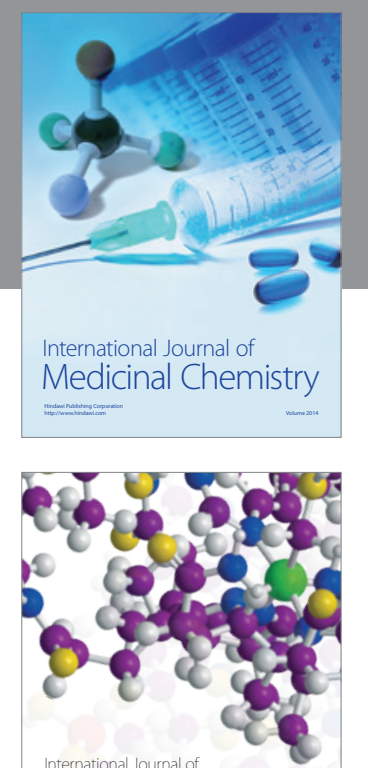

\section{Carbohydrate} Chemistry

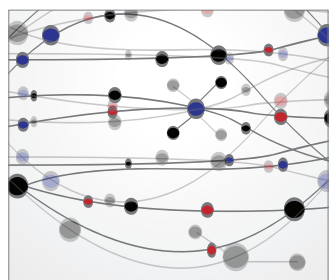

The Scientific World Journal
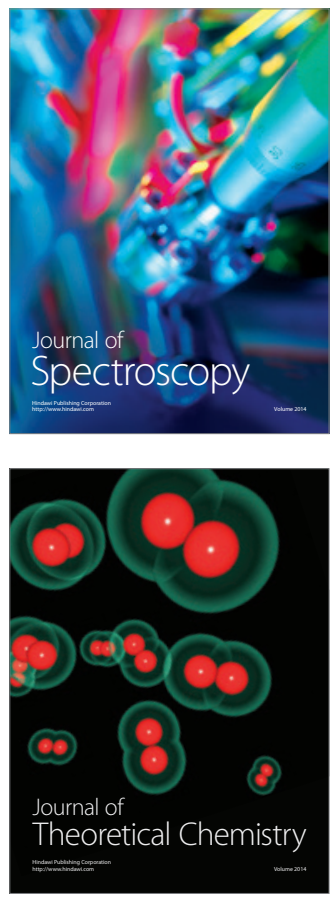
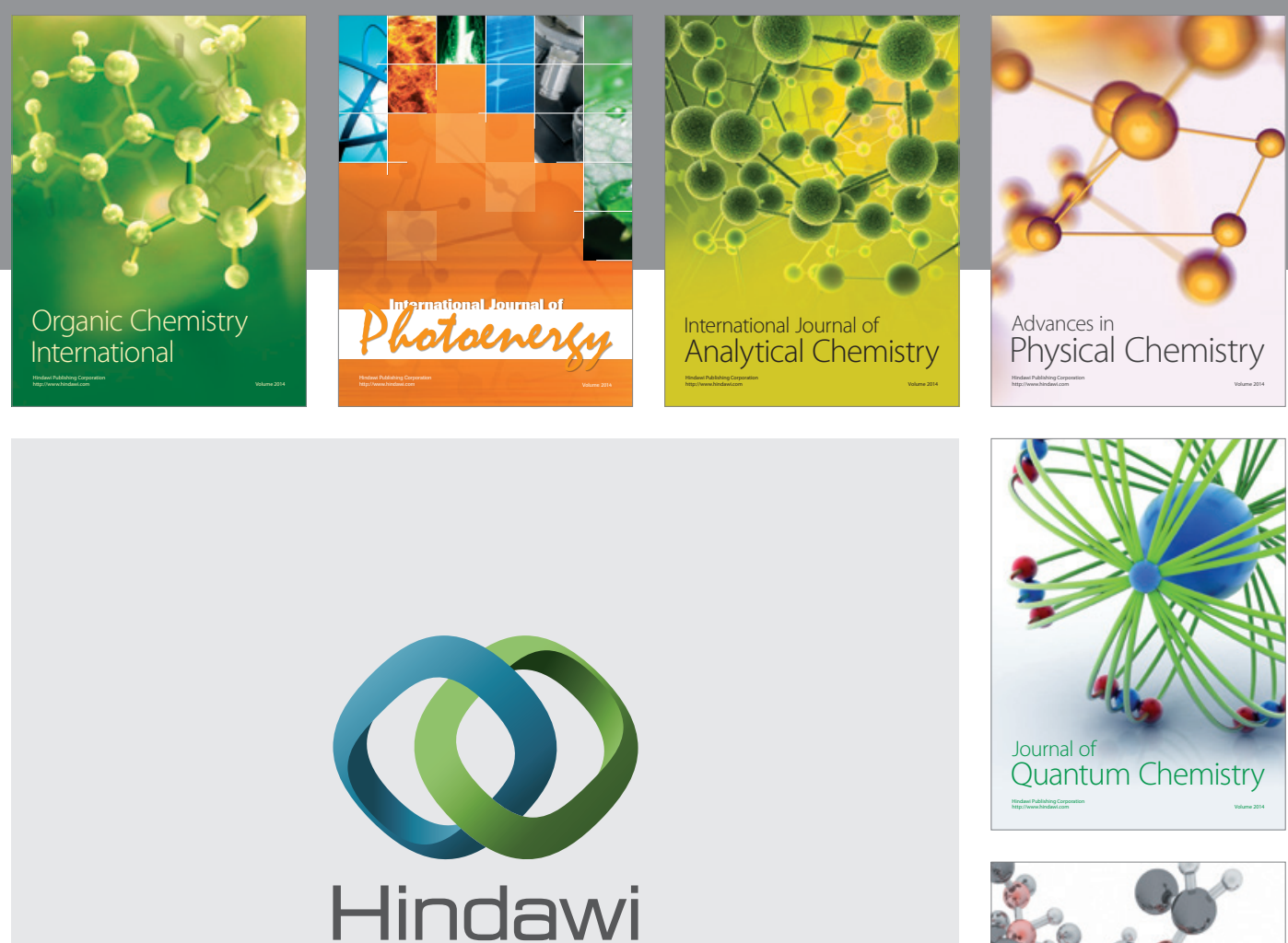

Submit your manuscripts at

http://www.hindawi.com

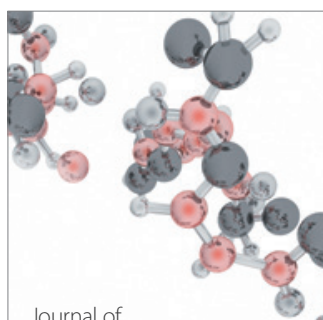

Analytical Methods

in Chemistry

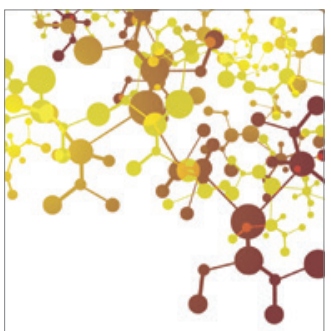

Journal of

Applied Chemistry

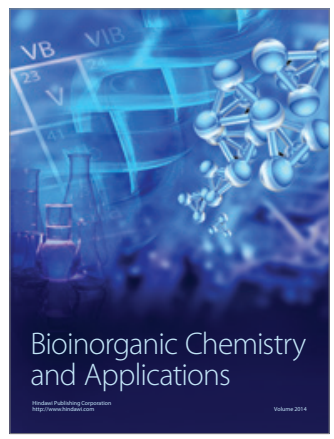

Inorganic Chemistry
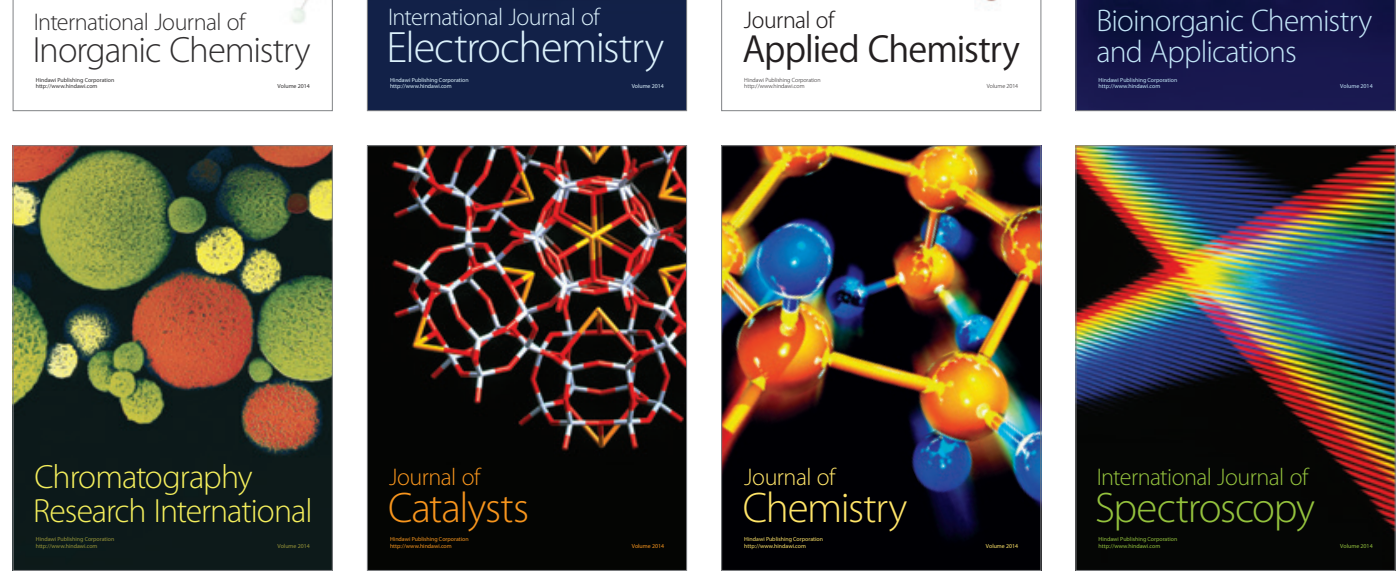